\title{
Effect of Allicin against Ischemia/Hypoxia-Induced H9c2 Myoblast Apoptosis via eNOS/NO Pathway-Mediated Antioxidant Activity
}

\author{
Lina Ma $\left(\mathbb{D},{ }^{1}\right.$ Shangke Chen $\left(\mathbb{D},{ }^{2}\right.$ Shaochun Li $\mathbb{D},{ }^{1,3}$ Lijuan Deng $\mathbb{D}{ }^{2}$, \\ Yikui Li $\mathbb{D}^{1},{ }^{1}$ and Hao Li $\mathbb{D}^{1}$ \\ ${ }^{1}$ Xiyuan Hospital, China Academy of Chinese Medical Sciences, Beijing, China \\ ${ }^{2}$ Xinjiang Ailexin Pharmaceutical Co., Ltd., Urumqi, Xinjiang, China \\ ${ }^{3}$ School of Basic Medical Sciences, Hebei University, Baoding, Hebei, China \\ Correspondence should be addressed to Yikui Li; lyk611@163.com and Hao Li; xyhplihao1965@126.com
}

Received 25 October 2017; Revised 28 February 2018; Accepted 11 March 2018; Published 16 April 2018

Academic Editor: Letizia Angiolella

Copyright $\odot 2018$ Lina Ma et al. This is an open access article distributed under the Creative Commons Attribution License, which permits unrestricted use, distribution, and reproduction in any medium, provided the original work is properly cited.

\begin{abstract}
Allicin (2-propene-1-sulfinothioic acid S-2-propenyl ester, diallyl thiosulfinate) is the main biologically active ingredient in garlic. The present study investigated the protective effect of allicin against cardiomyocyte apoptosis that was induced by ischemia in vitro and the potential molecular mechanisms that were involved in this antiapoptotic effect. The results indicated that allicin increased $\mathrm{H} 9 \mathrm{c} 2$ cell activity and attenuated the rate of apoptosis that was induced by ischemia/hypoxia. Intracellular calcium concentrations significantly decreased in the allicin-treated groups. Bax expression significantly decreased, and Bcl-2 expression increased in allicin-treated rats. Nitric oxide blockade significantly inhibited these effects. Allicin also increased the activity of SOD and NO release and decreased MDA levels. Allicin significantly increased the expression of eNOS, Nrf2, and HO-1 proteins. Collectively, these findings demonstrate that allicin protects $\mathrm{H} 9 \mathrm{c} 2$ cells against apoptosis, and this protective effect appears to occur via eNOS/NO pathway-mediated antioxidant activity.
\end{abstract}

\section{Introduction}

Ischemic heart disease (IHD) is one of the leading causes of global mortality, thus resulting in substantial social burdens worldwide [1-3]. Several studies have suggested that apoptosis occurs during the overall pathophysiological process of ischemia and plays an important role in the progression of cardiovascular diseases $[4,5]$. Apoptosis is a pivotal form of cell death after acute myocardial infarction, which leads to abnormal loading conditions and, further, left ventricular dilatation and consequently symptomatic heart failure $[6,7]$. Therefore, the inhibition of apoptosis may be an effective way to prevent heart failure and improve cardiac function. Numerous cardiovascular protective compounds have been discovered to limit the ischemic damage, but no satisfactory drug treatments have been developed for clinical practice.

Natural antioxidants from food sources have been used to prevent and treat IHD. Garlic has attracted particular attention because of its beneficial cardiovascular effects [8]. Allicin (2-propene-1-sulfinothioic acid S-2-propenyl ester, diallyl thiosulfinate) is the main biologically active ingredient in garlic. Allicin has been shown to exert a wide range of biological effects, including antioxidant activity, the inhibition of platelet activation, antitumor activity, and antimicrobial activity [9-12]. Our previous studies in rats found that allicin mitigates ischemic injury via inhibiting apoptosis [13]. It was also shown to prevent against myocardial apoptosis and fibrosis in a streptozotocin-induced diabetic models in rats [14]. Although abundant evidence supports a link between allicin and cardioprotection, the precise mechanisms by which allicin prevents IHD remain largely unknown. Therefore, the present study evaluated the protective effects of allicin against cardiomyocyte apoptosis that was induced by ischemia in vitro and investigated the potential molecular mechanisms that are involved in this antiapoptotic effect. 


\section{Materials and Methods}

2.1. Materials. Allicin injection $(5 \mathrm{mg} / \mathrm{ml})$ was obtained from Xinjiang Ailexin Pharmacy Co., Ltd. (Urumqi, China). NGnitro-L-arginine methyl ester (L-NAME), a specific pharmacological blocker of nitric oxide $(\mathrm{NO})$, was purchased from Sigma (St. Louis, MO, USA). Anti- $\beta$-actin antibody was purchased from Beijing Zhongshan Golden Bridge Biotechnology (Beijing, China). Antibodies against Bax and Bcl-2 were purchased from Cell Signaling Technology (Danvers, MA, USA). Antibodies against endothelial nitric oxide synthase (eNOS), nuclear factor erythroid 2-related factor 2 (Nrf2), and heme oxygenase-1 (HO-1) were purchased from Abcam (Cambridge, UK). Horseradish peroxidase- (HRP-) conjugated anti-mouse and anti-rabbit immunoglobulin $\mathrm{G}$ antibodies were purchased from Beijing Zhongshan Golden Bridge Biotechnology (Beijing, China).

2.2. H9c2 Cell Culture and Ischemia/Hypoxia Model. H9c2 cells were cultured in Dulbecco's modified Eagle's medium (DMEM) that contained $10 \%$ fetal bovine serum, $2 \mathrm{mM}$ glutamine, and antibiomycin (10 $\mathrm{mM}$ penicillin $\mathrm{G}$ and $10 \mathrm{mM}$ streptomycin) at $37^{\circ} \mathrm{C}$ in a humidified $5 \% \mathrm{CO}_{2}$ atmosphere and subcultured to approximately $80-90 \%$ confluence preexperimentally.

An $\mathrm{I} / \mathrm{H}$ model was established to induce apoptosis. The culture medium was replaced with serum-free DMEM, and then $\mathrm{H} 9 \mathrm{c} 2$ cells were transferred to a hypoxia chamber that was controlled by a ProOxC system balanced with $5 \%$ $\mathrm{CO}_{2} / 95 \% \mathrm{~N}_{2}$ at $37^{\circ} \mathrm{C}$ (Biospherix, Redfield, NY). The $\mathrm{O}_{2}$ concentration was $\leq 1 \%$. The cells were pretreated with allicin at different concentrations $(0.2,1$, and $5 \mu \mathrm{M})$ for $1 \mathrm{~h}$ and then exposed to $\mathrm{I} / \mathrm{H}$ for $12 \mathrm{~h}$. The negative control cells were cultured in DMEM containing 10\% fetal bovine serum without allicin.

2.3. Cell Viability Assay. Cell viability was examined using a 3-(4,5-dimethylthiazol-2-yl)-2,5-diphenyltetrazolium bromide (MTT) assay kit (Promega, Madison, WI, USA) according to the manufacturer's protocol. H9c2 cells were plated in 96-well plates at a density of $1 \times 10^{4}$ cells/well. The cells were pretreated with various doses of allicin $(0.2,1$, and $5 \mu \mathrm{M})$ for $1 \mathrm{~h}$ and then exposed to $\mathrm{I} / \mathrm{H}$ for $12 \mathrm{~h}$. Afterward, a $100 \mu \mathrm{l}$ cell suspension was incubated with $20 \mu \mathrm{l}$ of CellTiter $96^{\circledR}$ AQueous One Solution Reagent for $1 \mathrm{~h}$ with $5 \% \mathrm{CO}_{2}$ at $37^{\circ}$. Absorbance was read at $490 \mathrm{~nm}$. The mean optical density (OD) of five wells was used to calculate the percentage of cell viability: \% cell viability $=\mathrm{OD}_{\text {treatment group }} / \mathrm{OD}_{\text {control group }} \times$ $100 \%$.

2.4. Flow Cytometry Assay. The rate of apoptosis was determined by flow cytometry after staining the cells with Annexin V-FITC/PI (key GEN Bio TECH, Nanjing, China) according to the manufacturer's protocol. The cells were cultured in six-well plates at a density of $1 \times 10^{5}$ cells/well, treated with allicin $(0.2,1$, and $5 \mu \mathrm{M})$ for $1 \mathrm{~h}$, and then exposed to $\mathrm{I} / \mathrm{H}$ for $12 \mathrm{~h}$. The cells were harvested, washed twice with cold $1 \mathrm{x}$ phosphate-buffered saline (PBS), centrifuged at 2000 rotations per minute for $6 \mathrm{~min}$, and resuspended in $0.5 \mathrm{ml}$ of cold $1 \mathrm{x}$ binding buffer. The cell suspension was stained with $5 \mu \mathrm{l}$ of Annexin V-FITC for $10 \mathrm{~min}$ in the dark, and $5 \mu \mathrm{l}$ of propidium iodide (PI) was then added for 5-15 min in the light at room temperature. Flow cytometry was performed using a fluorescence-activated cell sorting instrument. The data were analyzed using WinMDI/PC software.

2.5. Measurement of Calcium Ion Concentrations. The cells were pretreated with various doses of allicin $(0.2,1$, and $5 \mu \mathrm{M})$ for $1 \mathrm{~h}$ and then subjected to $\mathrm{I} / \mathrm{H}$ for $12 \mathrm{~h}$. The cells were then incubated with Fluo-3/AM (Molecular Probes, USA) for $30 \mathrm{~min}$ at $37^{\circ} \mathrm{C}$ and then observed under a confocal laser scanning microscope.

2.6. Measurement of Oxidative Activity. The content of NO and malondialdehyde (MDA) and activity of sodium oxide dismutase (SOD) were assessed using specific kits (Nanjing Jiancheng Biological Engineering Institute, Nanjing, China). All of the procedures were performed according to the manufacturer's protocols.

2.7. Western Blot. Cell lysates ( $20 \mu \mathrm{g}$ of protein) were analyzed by $12 \%$ sodium dodecyl sulfate-polyacrylamide gel electrophoresis and electrotransferred to polyvinylidene difluoride membranes. The membranes were blocked with $5 \%$ bovine serum albumin and then probed with specific antibodies at $4^{\circ} \mathrm{C}$ overnight. After three washes in Tris PBS (TPBS), the membranes were incubated with HRPconjugated secondary antibodies, followed by electrochemiluminescent detection. Blot densitometry was then performed. The bands were analyzed using a Gene Genius Bio Imaging System.

2.8. Statistical Analyses. The data were analyzed using SPSS 19.0 software. The values are expressed as mean \pm SEM. Analysis of variance (ANOVA) was conducted, followed by Bonferroni correction, to test for differences in mean values between groups. The results were considered significant at $p<0.05$.

\section{Results}

3.1. Allicin Improves H9c2 Cell Morphology and Viability. Morphological variations of $\mathrm{H} 9 \mathrm{c} 2$ cells were observed under an inverted microscope. In the $\mathrm{I} / \mathrm{H}$ group, the cells were severely damaged, with edge blurring, shrunken, shedding, and floating in the cell culture medium. In the allicinpretreated groups, the degree of cell injury decreased, and cellular survival increased, especially in the group that was pretreated with $5 \mu \mathrm{M}$ allicin (Figure 1(a)).

Cell viability was examined using the MTT assay kit. Cell viability in the $\mathrm{I} / \mathrm{H}$ group significantly decreased compared with the control $(p<0.05)$. Cell viability significantly increased in the groups that were treated with 1 and $5 \mu \mathrm{M}$ allicin compared with the untreated I/H group $(p<0.05)$. No significant difference $(p>0.05)$ was observed between the 


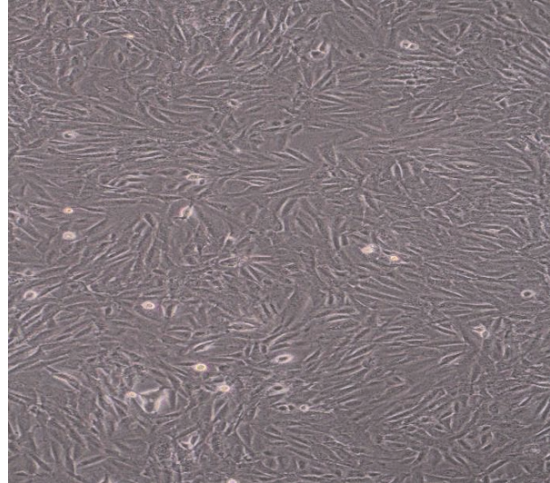

Control

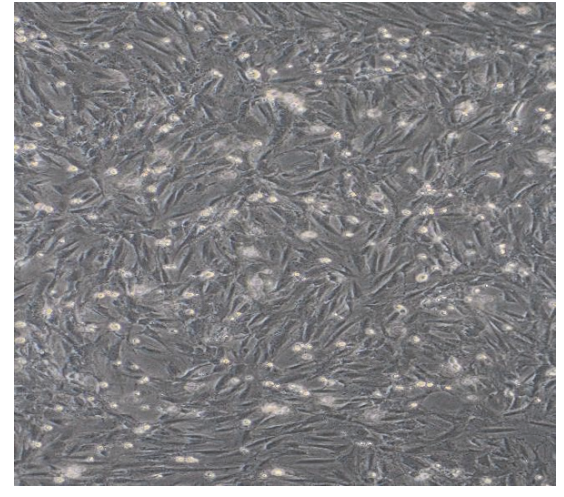

$\mathrm{I} / \mathrm{H}$

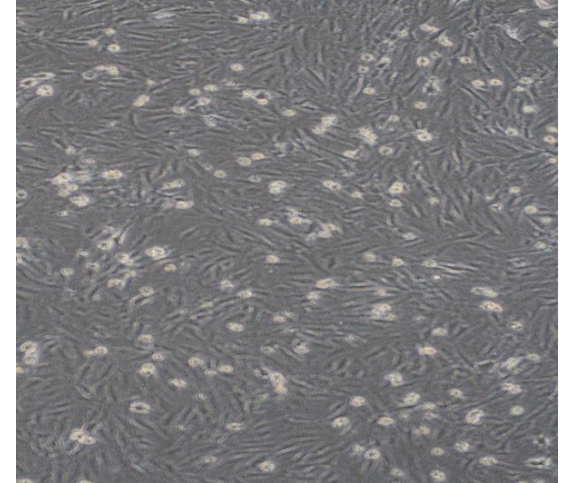

$\mathrm{I} / \mathrm{H}+\mathrm{AL}(0.2 \mu \mathrm{M})$

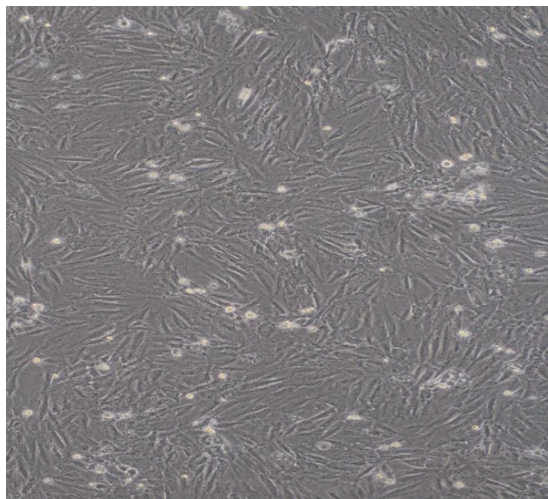

$\mathrm{I} / \mathrm{H}+\mathrm{AL}(1 \mu \mathrm{M})$

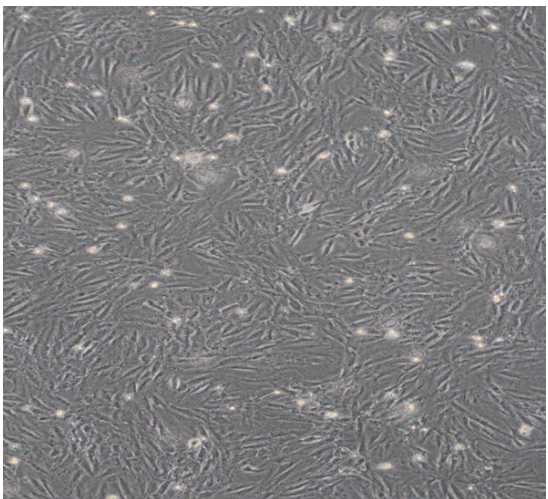

$\mathrm{I} / \mathrm{H}+\mathrm{AL}(5 \mu \mathrm{M})$

(a)

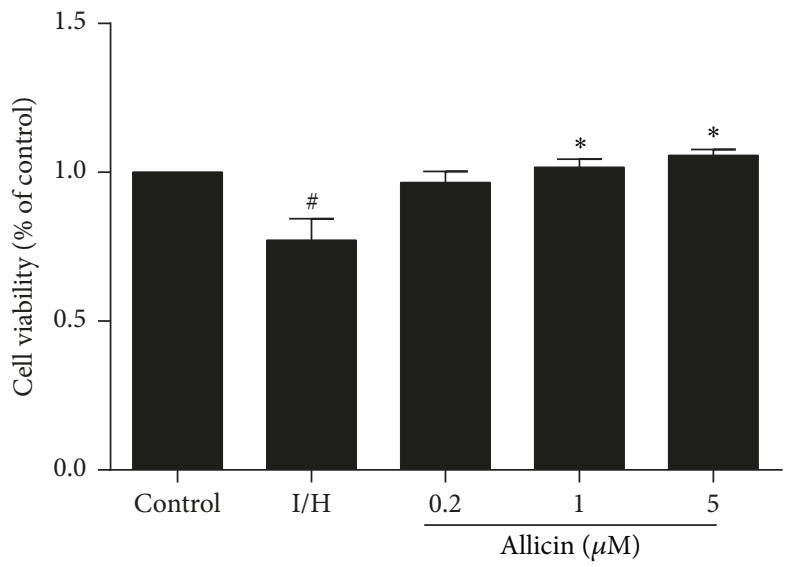

(b)

Figure 1: Cell morphology (40x magnification) and viability in $\mathrm{H} 9 \mathrm{c} 2$ cells that were pretreated with allicin and subjected to I/H, evaluated in the MTT assay. (a) Representative images of H9c2 cells of the five groups during I/H. (b) Effect of allicin on cell viability. Five groups were evaluated: one group of control cells that were not pretreated with allicin and not subjected to $\mathrm{I} / \mathrm{H}$, one group of untreated H9c2 cells that were subjected to $\mathrm{I} / \mathrm{H}$, and three groups of $\mathrm{H} 9 \mathrm{c} 2$ cells that were pretreated with $0.2,1$, and $5 \mu \mathrm{M}$ allicin and subjected to $\mathrm{I} / \mathrm{H}$. $n=3$ independent experiments. The data are expressed as mean \pm SEM. ${ }^{*} p<0.05$, compared with control; ${ }^{*} p<0.05$, compared with I/H. I/H, ischemia/hypoxia; AL, allicin.

group that was treated with $0.2 \mu \mathrm{M}$ allicin and the untreated I/H group (Figure 1(b)).

3.2. Allicin Decreases Rate of $\mathrm{I} / \mathrm{H}$-Induced Apoptosis in H9c2 Cells. After incubation under conditions of $\mathrm{I} / \mathrm{H}$ for $12 \mathrm{~h}$, the rate of apoptosis was determined by flow cytometry after staining the cells with Annexin V-FITC/PI. In the untreated $\mathrm{I} / \mathrm{H}$ group, apoptosis significantly increased compared with the sham control group $(p<0.05)$. Apoptosis in the allicintreated groups significantly decreased compared with the untreated I/H group $(p<0.05$; Figure 2$)$. 

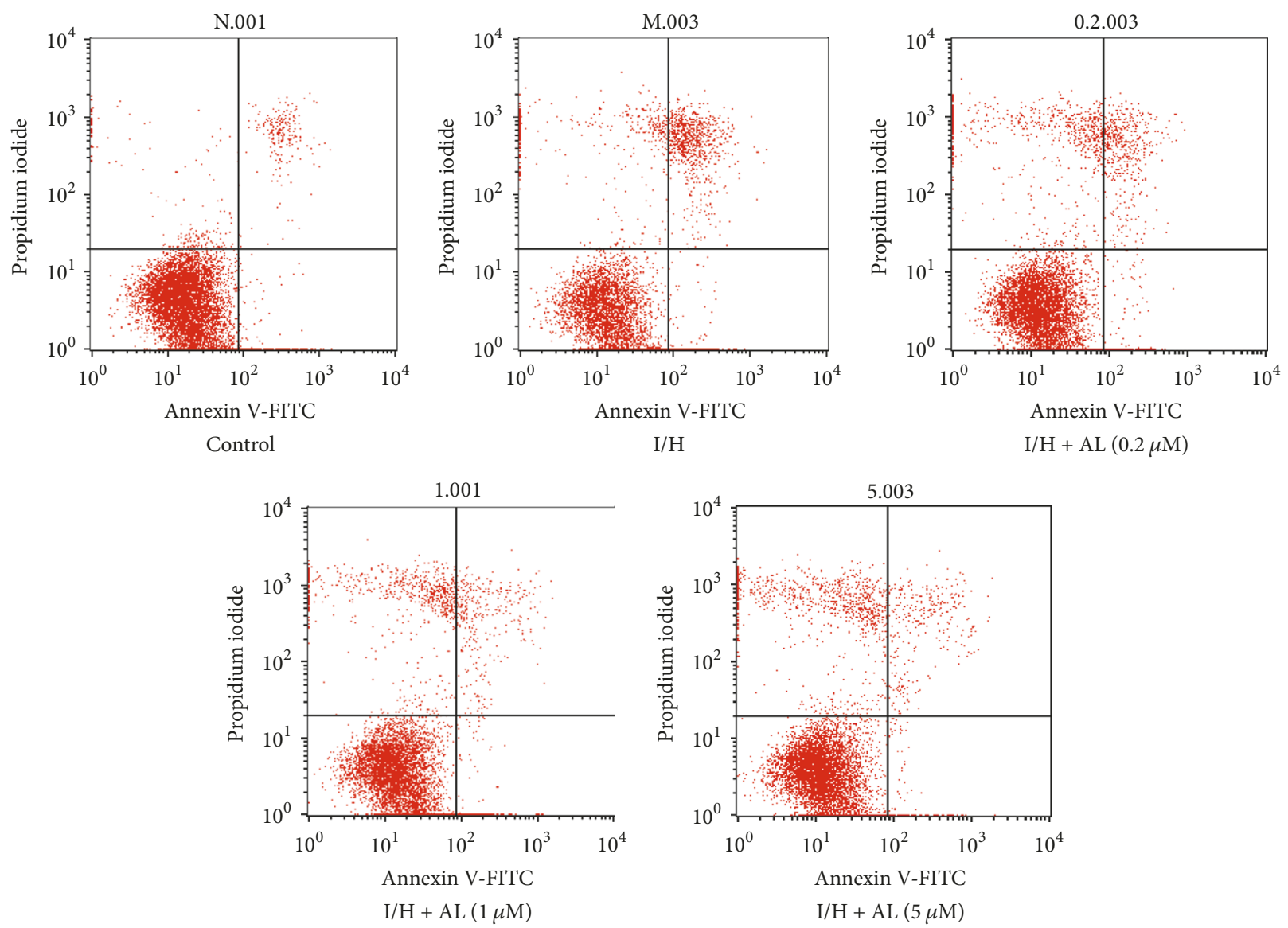

(a)

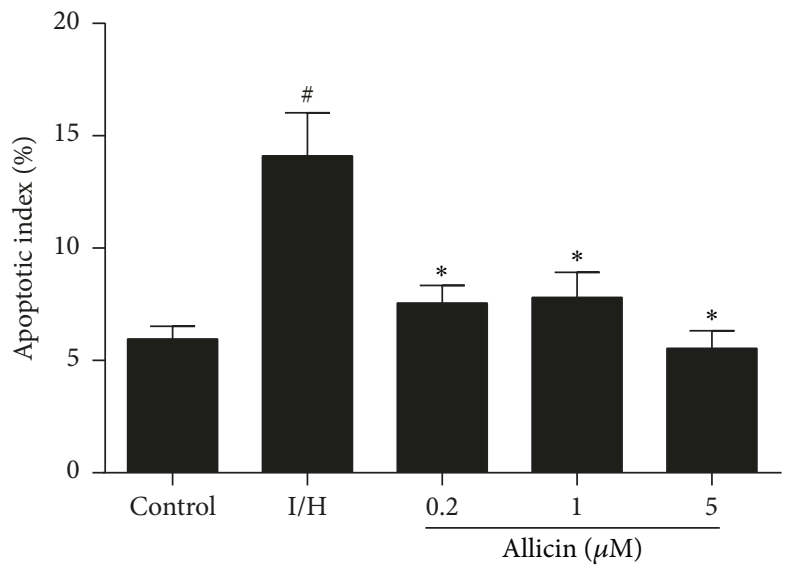

(b)

FIGURE 2: Effect of allicin on rate of $\mathrm{I} / \mathrm{H}$-induced apoptosis in $\mathrm{H} 9 \mathrm{c} 2$ cells, assessed by flow cytometry. (a) Representative images of H9c2 cell apoptosis during I/H. (b) Effect of allicin on rate of apoptosis. Five groups were evaluated: one group of control cells that were not pretreated with allicin and not subjected to $\mathrm{I} / \mathrm{H}$, one group of untreated $\mathrm{H} 9 \mathrm{c} 2$ cells that were subjected to $\mathrm{I} / \mathrm{H}$, and three groups of $\mathrm{H} 9 \mathrm{c} 2$ cells that were pretreated with $0.2,1$, and $5 \mu \mathrm{M}$ allicin and subjected to $\mathrm{I} / \mathrm{H} . n=3$ independent experiments. The data are expressed as mean \pm SEM. ${ }^{\#} p<0.05$, compared with control; ${ }^{*} p<0.05$, compared with $\mathrm{I} / \mathrm{H}$. I/H, ischemia/hypoxia; AL, allicin.

3.3. Allicin Decreases Intracellular $\mathrm{Ca}^{2+}$ Concentrations. To detect intracellular $\mathrm{Ca}^{2+}$ concentrations, the cells were incubated with Fluo-3/AM and then observed under a confocal laser scanning microscope. $\mathrm{Ca}^{2+}$ concentrations in the untreated I/H group significantly increased compared with the control group ( $p<0.05$; Figure 3$)$. In the allicin-treated groups, a significant decrease in $\mathrm{Ca}^{2+}$ concentrations was observed compared with the untreated I/H group $(p<0.05)$. 


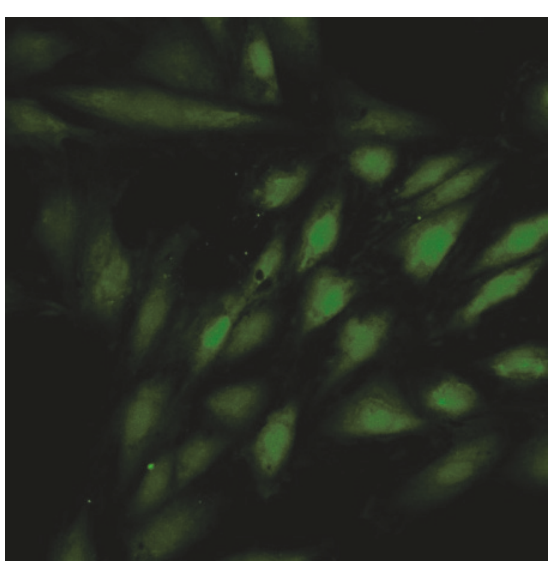

Control

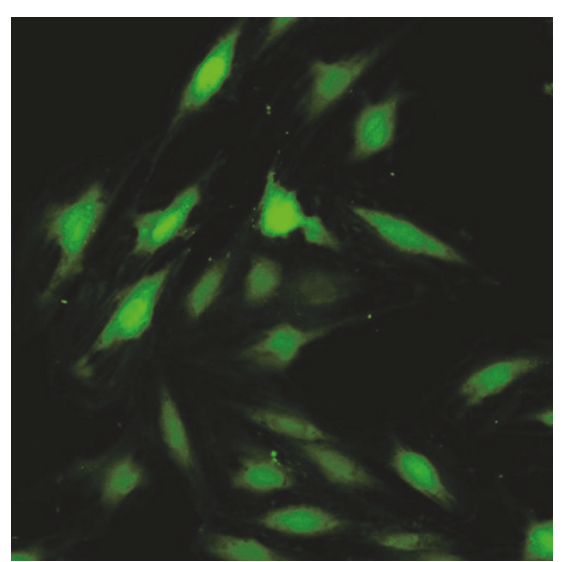

$\mathrm{I} / \mathrm{H}$

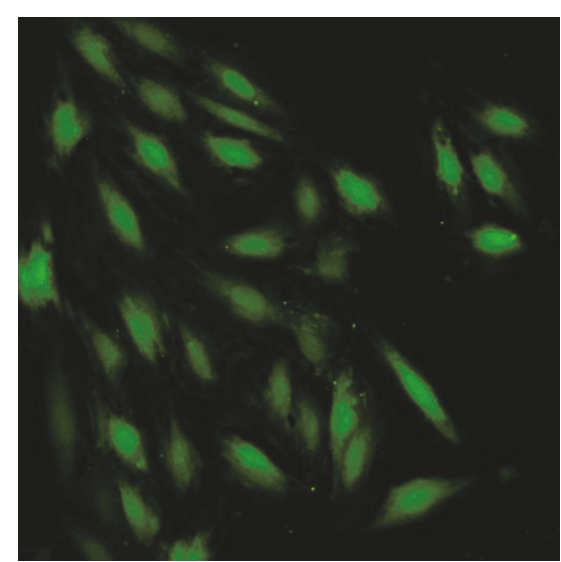

$\mathrm{I} / \mathrm{H}+\mathrm{AL}(0.2 \mu \mathrm{M})$

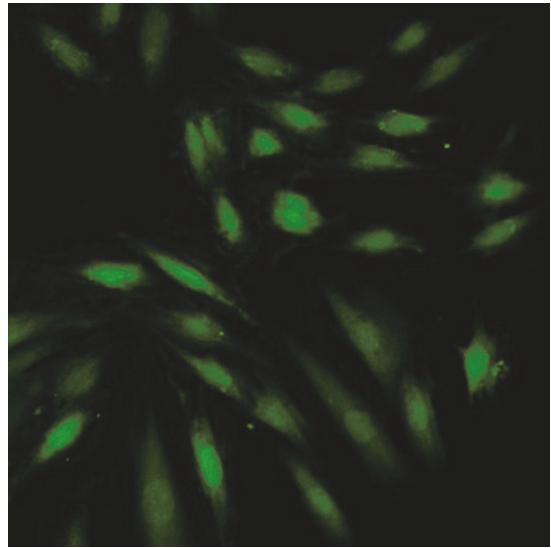

$\mathrm{I} / \mathrm{H}+\mathrm{AL}(1 \mu \mathrm{M})$

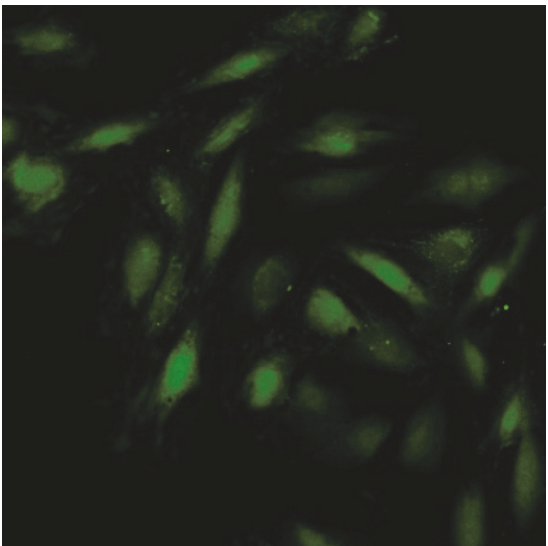

$\mathrm{I} / \mathrm{H}+\mathrm{AL}(5 \mu \mathrm{M})$

(a)

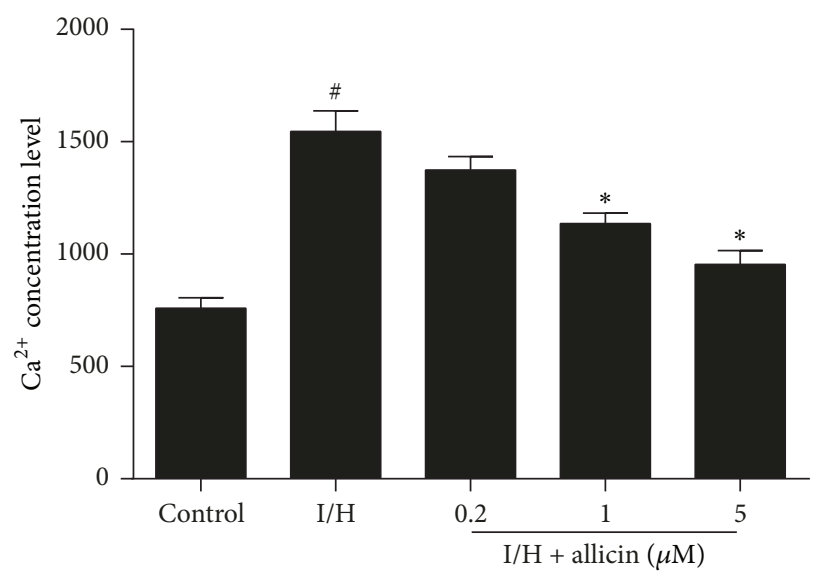

(b)

FIGURE 3: Effect of allicin on intracellular $\mathrm{Ca}^{2+}$ concentrations during $\mathrm{I} / \mathrm{H}$. (a) Representative images of intracellular $\mathrm{Ca}^{2+}$ concentrations in $\mathrm{H} 9 \mathrm{c} 2$ cells during I/H. (b) Effect of allicin on intracellular $\mathrm{Ca}^{2+}$ concentrations. Five groups were evaluated: one group of control cells that were not pretreated with allicin and not subjected to $\mathrm{I} / \mathrm{H}$, one group of untreated $\mathrm{H} 9 \mathrm{c} 2$ cells that were subjected to $\mathrm{I} / \mathrm{H}$, and three groups of $\mathrm{H} 9 \mathrm{c} 2$ cells that were pretreated with $0.2,1$, and $5 \mu \mathrm{M}$ allicin and subjected to $\mathrm{I} / \mathrm{H} . n=3$ independent experiments. The data are expressed as mean \pm SEM. ${ }^{*} p<0.05$, compared with control; ${ }^{*} p<0.05$, compared with I/H. I/H, ischemia/hypoxia; AL, allicin.

3.4. Allicin Suppresses the Expression of Markers of Apoptosis. $\mathrm{Bax}$ and $\mathrm{Bcl}-2$ are markers of apoptosis. Bax and $\mathrm{Bcl}-2$ protein expression was detected by Western blot. Bax expression significantly increased and Bcl-2 expression significantly decreased in $\mathrm{H} 9 \mathrm{c} 2$ cells that were subjected to $\mathrm{I} / \mathrm{H}$ compared with the control group. Bax expression significantly decreased in the group that was pretreated with $5 \mu \mathrm{M}$ allicin, and $\mathrm{Bcl}$ 2 expression significantly increased in the groups that were 

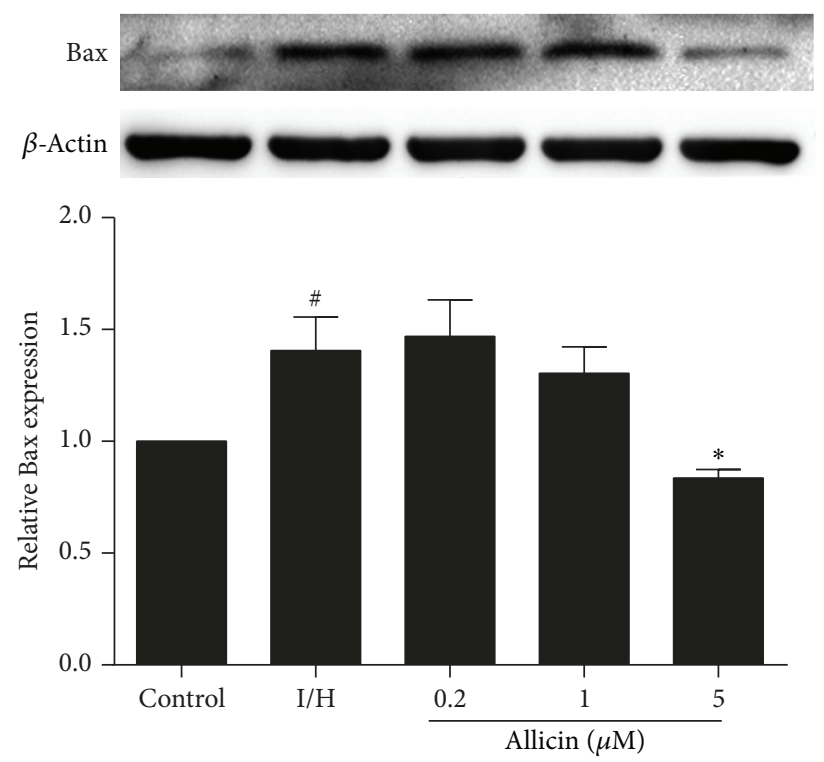

(a)
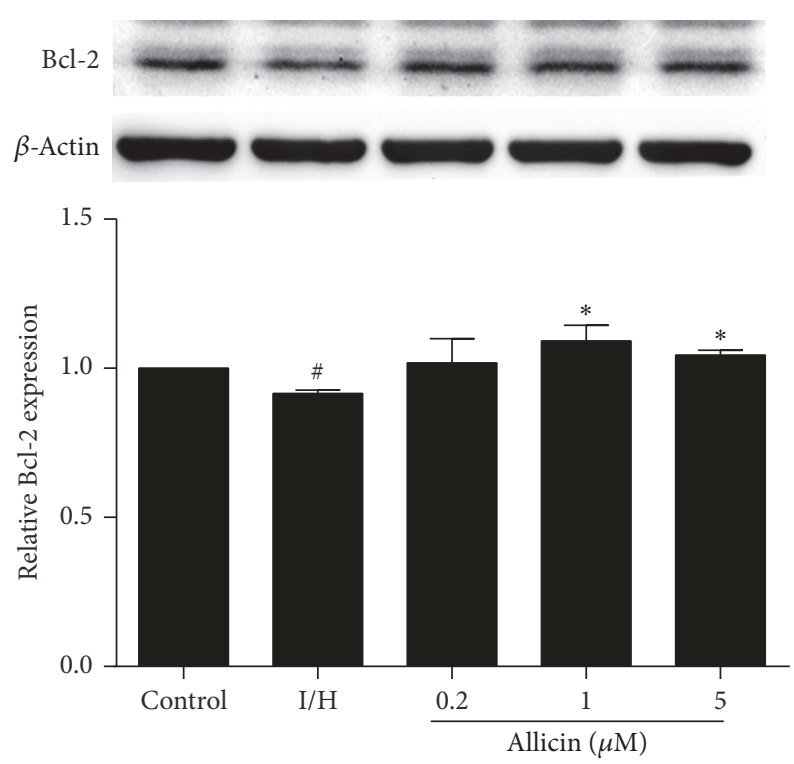

(b)

Figure 4: Effect of allicin on Bax and Bcl-2 expression in H9c2 cells, evaluated by Western blot. (a) Allicin decreased Bax expression. (b) Allicin increased Bcl-2 expression. Five groups were evaluated: one group of control cells that were not pretreated with allicin and not subjected to $\mathrm{I} / \mathrm{H}$, one group of untreated $\mathrm{H} 9 \mathrm{c} 2$ cells that were subjected to $\mathrm{I} / \mathrm{H}$, and three groups of $\mathrm{H} 9 \mathrm{c} 2$ cells that were pretreated with $0.2,1$, and $5 \mu \mathrm{M}$ allicin and subjected to I/H. $n=3$ independent experiments. The data are expressed as mean \pm SEM. ${ }^{*} p<0.05$, compared with control; ${ }^{*} p<0.05$, compared with $\mathrm{I} / \mathrm{H}$. $\mathrm{I} / \mathrm{H}$, ischemia/hypoxia; $\mathrm{AL}$, allicin.

pretreated with 1 and $5 \mu \mathrm{M}$ allicin ( $p<0.05$; Figures 4(a) and $4(\mathrm{~b}))$.

\subsection{Allicin Increases eNOS Expression and NO Levels. Nitric} oxide is a potent gaseous signaling molecule. eNOS-derived NO may participate in the pathophysiological regulation of ischemic heart disease. We detected eNOS expression and $\mathrm{NO}$ levels that were induced by $\mathrm{I} / \mathrm{H}$ in $\mathrm{H} 9 \mathrm{c} 2$ cells. eNOS expression significantly decreased in untreated cells that were subjected to $\mathrm{I} / \mathrm{H}$ compared with the control group $(p<$ $0.05)$. In the allicin-pretreated groups $(0.2,1$, and $5 \mu \mathrm{M})$, eNOS expression significantly increased compared with the untreated I/H group $(p<0.05$; Figure 5(a)). NO levels significantly decreased in untreated cells that were subjected to $\mathrm{I} / \mathrm{H}$ compared with the control group. In cells that were treated with allicin (1 and $5 \mu \mathrm{M})$, NO levels dose-dependently increased $(p<0.05$; Figure 5(b)).

3.6. Effect of L-NAME on Antiapoptotic Effect of Allicin. We used L-NAME, a specific pharmacological blocker of $\mathrm{NO}$, to elucidate the mechanism of action of allicin. LNAME significantly inhibited eNOS expression $(p<0.05$; Figure 6(a)) and inhibited the cardioprotective effect of allicin against apoptosis, reflected by an increase in Bax expression and decrease in Bcl-2 expression $(p<0.05$; Figures $6(\mathrm{~b})$ and $6(c))$.

3.7. Effect of Allicin on Oxidative Activity in $\mathrm{H} 9 \mathrm{c} 2$ Cells. Malondialdehyde and SOD are biomarkers of oxidative stress. To determine whether allicin functions at the level of oxidative stress, we measured MDA and SOD in $\mathrm{H} 9 \mathrm{c} 2$ cells. Our results showed that MDA levels significantly increased and SOD activity significantly decreased during $\mathrm{I} / \mathrm{H}$, and these effects were reversed by allicin pretreatment (Figures 7(a) and 7(b)).

3.8. Effect of Allicin on Nrf2 and HO-1 Expression in H9c2 Cells. We further examined whether allicin affects activation of the Nrf2/HO-1 signaling pathway. $\mathrm{I} / \mathrm{H}$ induced a trend toward higher Nrf2 expression in H9c2 cells $(p>0.05)$. Treatment with allicin $(1$ and $5 \mu \mathrm{M})$ significantly increased Nrf2 expression ( $p<0.05$; Figure $8(a))$. Moreover, I/H significantly increased $\mathrm{HO}-1$ expression in $\mathrm{H} 9 \mathrm{c} 2$ cells. Treatment with allicin $(1$ and $5 \mu \mathrm{M})$ induced a further dose-dependent increase in HO-1 expression $(p<0.05$; Figure $8(\mathrm{~b}))$.

\section{Discussion}

Allicin is one of the critical bioactive organosulfur compounds in garlic. It has been reported to have a number of bioactivities including antioxidant, cardioprotective activity $[15,16]$. However, due to its unstable nature, allicin is rapidly degraded with time depending on environmental and processing conditions, such as temperature, light, and concentration [17-19]. Document has also shown that the biological half-life of allicin is significantly longer in alcoholic and aqueous extracts than the chemical one [20]. In the present study, allicin is a water-soluble injection and stored in dark place at $4^{\circ} \mathrm{C}$ to ensure its stability. Then, we assessed the antiapoptotic effect of allicin in H9c2 cells. Allicin significantly decreased intracellular calcium concentration and the 


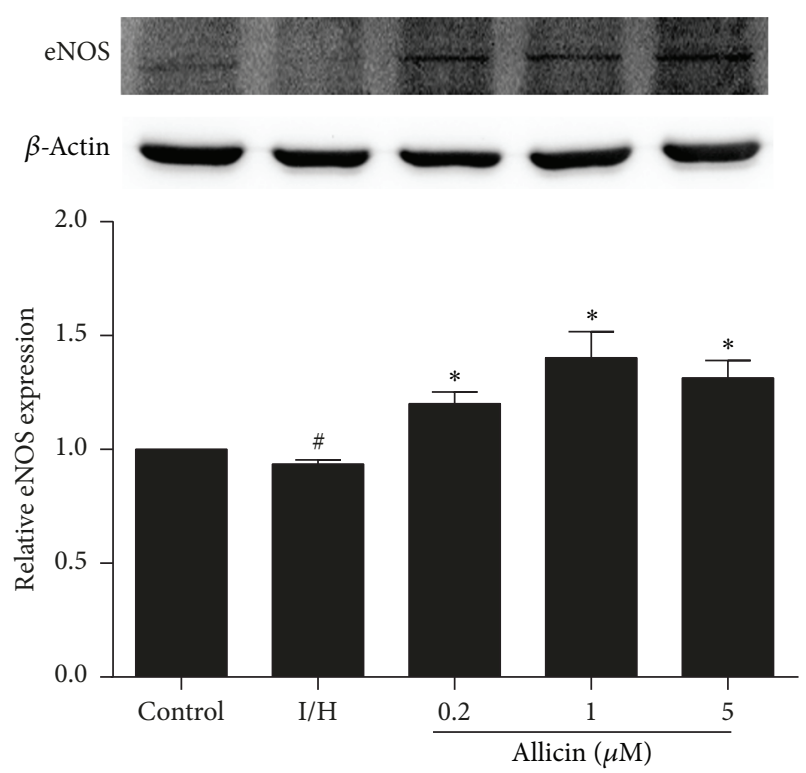

(a)

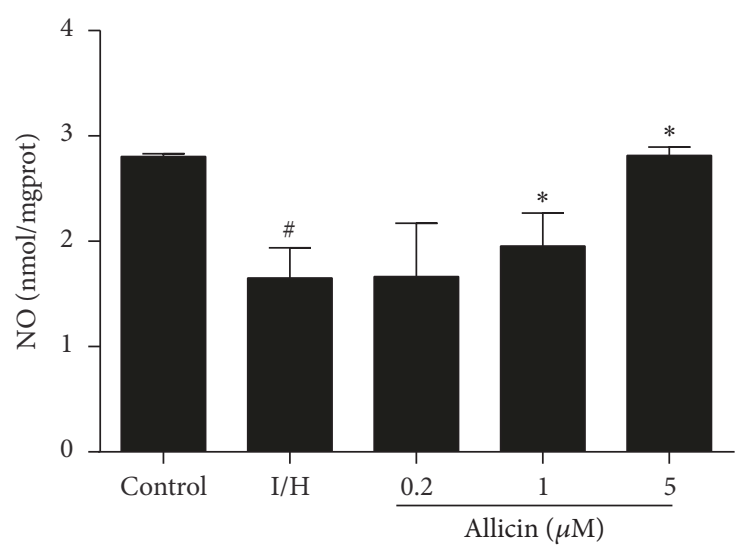

(b)

Figure 5: Effect of allicin on eNOS expression and NO levels in H9c2 cells. (a) Allicin increased eNOS expression. (b) Allicin increased NO levels. Five groups were evaluated: one group of control cells that were not pretreated with allicin and not subjected to I/H, one group of untreated $\mathrm{H} 9 \mathrm{c} 2$ cells that were subjected to $\mathrm{I} / \mathrm{H}$, and three groups of $\mathrm{H} 9 \mathrm{c} 2$ cells that were pretreated with $0.2,1$, and $5 \mu \mathrm{M}$ allicin and subjected to I/H. $n=3$ independent experiments. The data are expressed as mean \pm SEM. ${ }^{*} p<0.05$, compared with control; ${ }^{*} p<0.05$, compared with $\mathrm{I} / \mathrm{H}$. I/H, ischemia/hypoxia; AL, allicin.

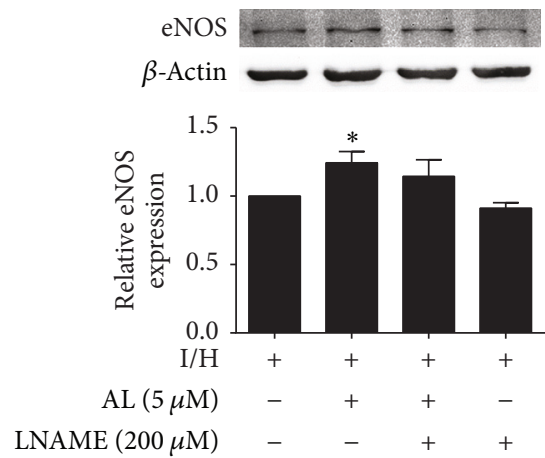

(a)

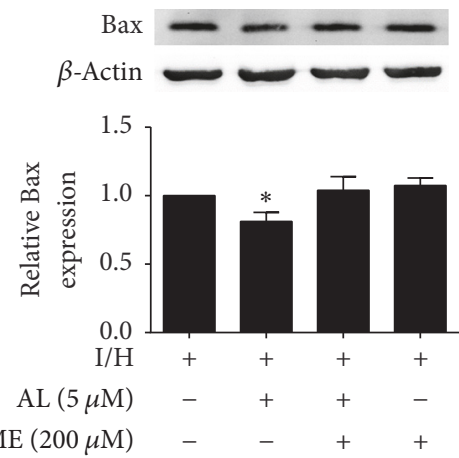

(b)

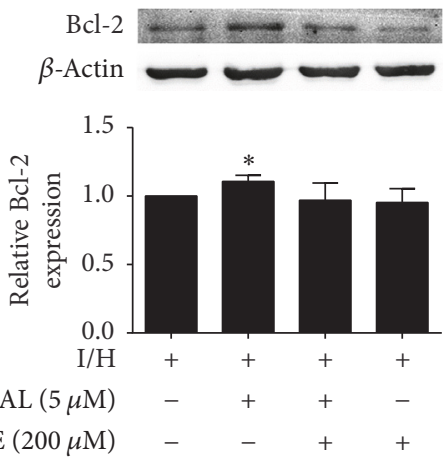

(c)

FiguRE 6: Effect of allicin and L-NAME on the expression of (a) eNOS, (b) Bax, and (c) Bcl-2 in H9c2 cells, evaluated by Western blot. Four groups were evaluated: one group of $\mathrm{H} 9 \mathrm{c} 2$ cells that were not treated with either allicin or L-NAME and were subjected to $\mathrm{I} / \mathrm{H}$, one group of $\mathrm{H} 9 \mathrm{c} 2$ cells that were pretreated with $5 \mu \mathrm{M}$ allicin and subjected to $\mathrm{I} / \mathrm{H}$, one group of $\mathrm{H} 9 \mathrm{c} 2$ cells that were pretreated with $5 \mu \mathrm{M}$ allicin and $200 \mu \mathrm{M} \mathrm{L}-\mathrm{NAME}$ and subjected to $\mathrm{I} / \mathrm{H}$, and one group of $\mathrm{H} 9 \mathrm{c} 2$ cells that were pretreated with $200 \mu \mathrm{M}$ L-NAME and subjected to I/H. $n=3$ independent experiments. The data are expressed as mean \pm SEM. ${ }^{*} p<0.05$, compared with $\mathrm{I} / \mathrm{H}$. I/H, ischemia/hypoxia; AL, allicin.

rate of apoptosis. Meanwhile, allicin significantly increased Bax expression and decreased Bcl-2 and eNOS expression. However, the NO blocker L-NAME partially reversed these beneficial effects of allicin, indicating an involvement of eNOS/NO signaling pathway. Allicin also increased SOD activity, NO release, and $\mathrm{Nrf} 2$ and $\mathrm{HO}-1$ expression and decreased MDA levels. Altogether, these findings suggest that activation of the eNOS/NO pathway by allicin and its antioxidant and antiapoptotic effects play an important role in its cardioprotective effects.
Apoptosis is a key regulator in the pathogenesis of myocardial ischemia. Bcl-2 family members act upstream of mitochondrial-mediated apoptosis and play a central role in cell fate and homeostasis. Bcl-2 (prosurvival) protein expression determines whether the cell undergoes apoptosis or reenters the cell cycle. Bax protein expression integrates important functions that are related to apoptosis and facilitates the release of cytochrome $c$ from mitochondria $[21,22]$. Therefore, the ratio of $\mathrm{Bcl}-2 / \mathrm{Bax}$ expression is regarded as a hallmark in cell survival or death upon apoptotic stimulation 


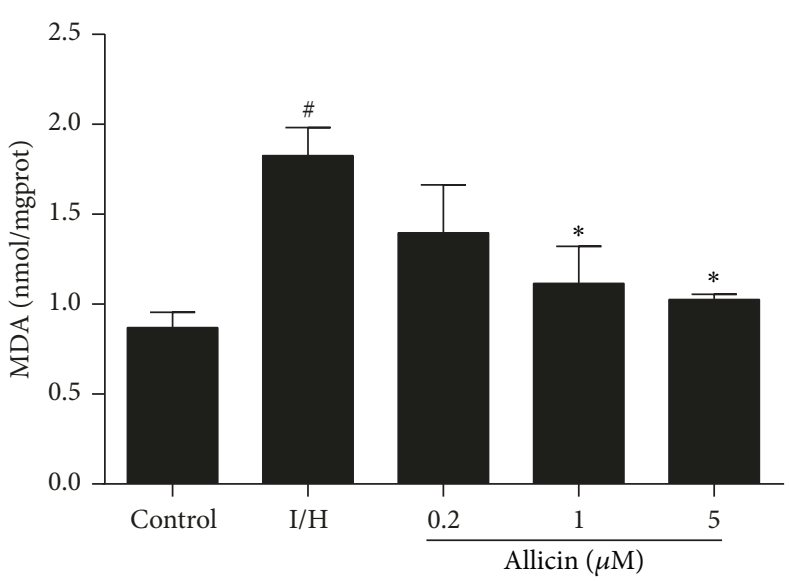

(a)

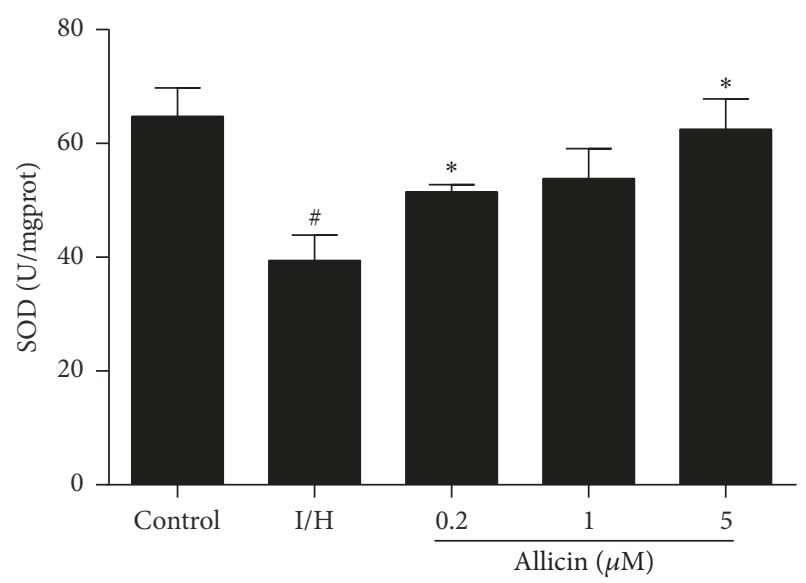

(b)

FIGURE 7: Effects of allicin on MDA and SOD levels in H9c2 cells. (a) Allicin downregulated MDA levels in H9c2 cells. (b) Allicin increased SOD activity in H9c2 cells. Five groups were evaluated: one group of control cells that were not pretreated with allicin and not subjected to $\mathrm{I} / \mathrm{H}$, one group of untreated $\mathrm{H} 9 \mathrm{c} 2$ cells that were subjected to $\mathrm{I} / \mathrm{H}$, and three groups of $\mathrm{H} 9 \mathrm{c} 2$ cells that were pretreated with $0.2,1$, and $5 \mu \mathrm{M}$ allicin and subjected to I/H. $n=3$ independent experiments. The data are expressed as mean \pm SEM. ${ }^{\#} p<0.05$, compared with control; ${ }^{*} p<0.05$, compared with $\mathrm{I} / \mathrm{H}$. $\mathrm{I} / \mathrm{H}$, ischemia/hypoxia; AL, allicin.

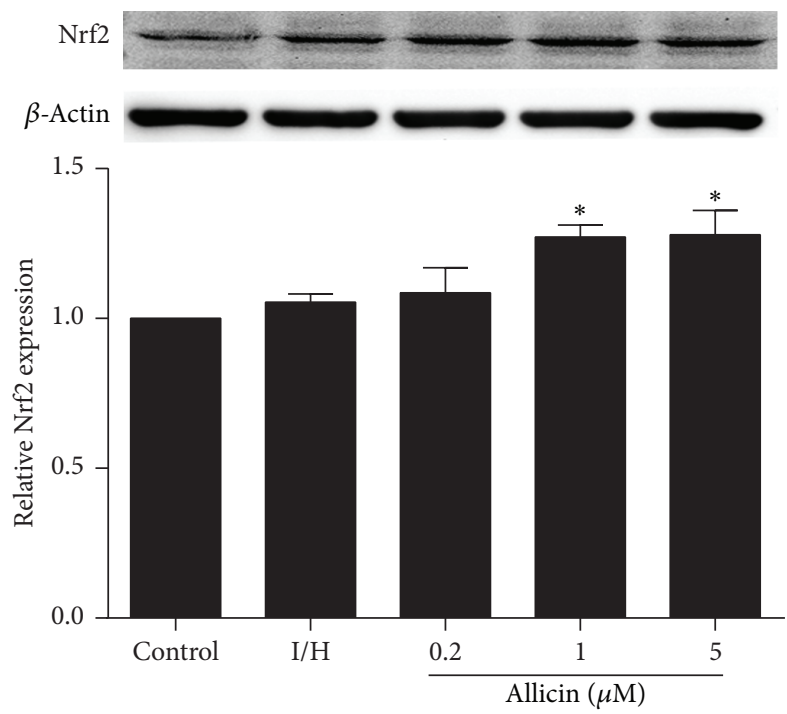

(a)

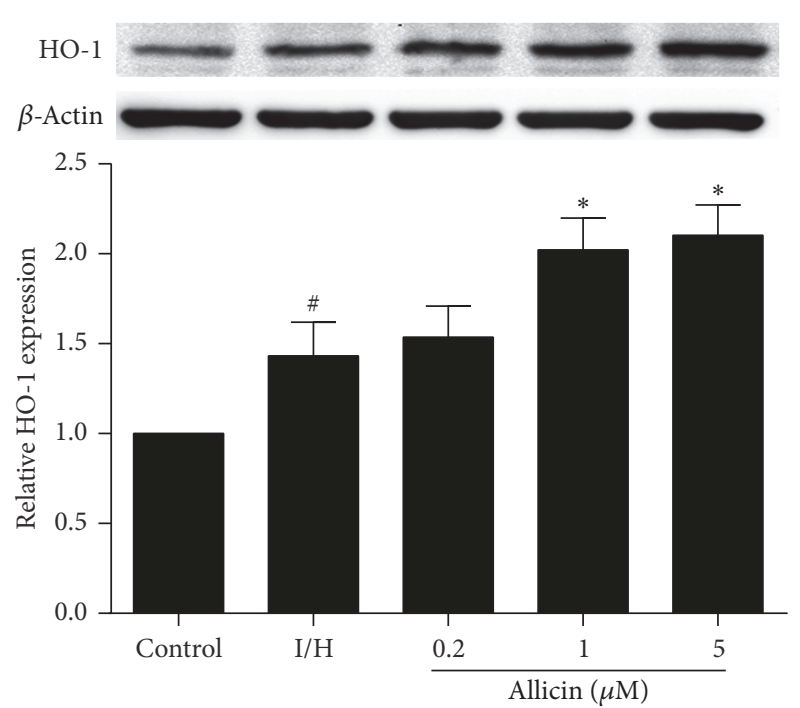

(b)

FIGURE 8: Effect of allicin on Nrf2 and HO-1 expression in H9c2 cells, evaluated by Western blot. (a) Allicin increased Nrf2 expression. (b) Allicin increased HO-1 expression. Five groups were evaluated: one group of control cells that were not pretreated with allicin and not subjected to $\mathrm{I} / \mathrm{H}$, one group of untreated $\mathrm{H} 9 \mathrm{c} 2$ cells that were subjected to $\mathrm{I} / \mathrm{H}$, and three groups of $\mathrm{H} 9 \mathrm{c} 2$ cells that were pretreated with $0.2,1$, and $5 \mu \mathrm{M}$ allicin and subjected to I/H. $n=3$ independent experiments. The data are expressed as mean \pm SEM. ${ }^{\#} p<0.05$, compared with control; ${ }^{*} p<0.05$, compared with $\mathrm{I} / \mathrm{H}$. I/H, ischemia/hypoxia; AL, allicin.

$[23,24]$. In the present study, we utilized $\mathrm{I} / \mathrm{H}$ method to induce apoptosis in $\mathrm{H} 9 \mathrm{c} 2$ cells, and allicin significantly increased cell activity and decreased the rate of apoptosis that was induced by $\mathrm{I} / \mathrm{H}$, reflected by a decrease in Bax expression and increase in $\mathrm{Bcl}-2$ expression. Cellular injury caused $\mathrm{I} / \mathrm{H}$ is also accompanied by intracellular calcium overload. Increasing intracellular $\mathrm{Ca}^{2+}$ contributes to the development and progression of myocardial apoptosis [25].
Our results showed that intracellular calcium concentrations significantly decreased in the allicin-pretreated groups.

Nitric oxide is a potent gaseous signaling molecule that is synthesized by a family of NOS enzymes, including inducible, neuronal, and endothelial forms [26]. eNOS, also known as NOS III, is a low-output enzyme that is constitutively expressed in $\mathrm{H} 9 \mathrm{c} 2$ cells. eNOS-derived NO has been reported to participate in the pathophysiology of ischemic 
heart disease, such as myocardial infarction and myocardial ischemia-reperfusion injury $[27,28]$. A previous study reported that both skin and flesh garlic extracts effectively prevented norepinephrine-induced cardiomyocyte hypertrophy and cell death, and these beneficial effects were partially mediated by $\mathrm{NO}$ and $\mathrm{H}_{2} \mathrm{~S}$ [29]. Our previous findings showed that plasma $\mathrm{H}_{2} \mathrm{~S}$ levels dose-dependently increased in allicintreated rats, indicating that allicin may be an $\mathrm{H}_{2} \mathrm{~S}$ donor [13]. The present study demonstrated the involvement of NO in this process. Allicin treatment increased eNOS protein expression and NO levels. To further explore the mechanism by which allicin attenuates myocardial cell apoptosis, we pharmacologically blocked NO using L-NAME. L-NAME significantly inhibited the cardioprotective effect of allicin against apoptosis, evidenced by an increase in Bax expression and decrease in Bcl-2 expression. These data strongly suggest that the eNOS/NO pathway is involved in the effects of allicin against apoptosis.

Oxidative stress promotes cell death in response to various pathophysiological conditions. Reaction oxygen species (ROS) are free radicals, the accumulation of which can cause oxidative stress that damages the heart in myocardial ischemia [30]. Previous studies reported that allicin protected cells against oxidative stress by inhibiting the generation of intracellular $\operatorname{ROS}[31,32]$. Nrf2 is a redoxsensitive transcription factor that plays a key role in cellular antioxidant defense [33]. In the presence of oxidative stress, $\mathrm{Nrf} 2$ is rapidly degraded by the proteasome system, enters the nucleus, binds to antioxidant response element, and upregulates multiple antioxidant and detoxifying genes, such as HO-1 [34]. Allicin was previously reported to prevent the development of cardiac remodeling and progression of cardiac hypertrophy to cardiac dysfunction by enhancing Nrf2 antioxidant signaling pathways [35]. A reasonable speculation is that the antiapoptotic effect of allicin may be associated with activation of the Nrf2 signaling pathway associated with oxidative stress. Therefore, we tested the effects of allicin on oxidative stress. Allicin significantly decreased MDA levels and increased SOD activity. It also promoted Nrf2 synthesis and nuclear translocation and further increased the expression of $\mathrm{HO}-1$ protein, indicating the antioxidative activity of allicin in our $\mathrm{I} / \mathrm{H}$ model. Numerous studies have shown that NO can scavenge ROS and attenuate the detrimental effects of ROS [36, 37]. In the present study, allicin increased eNOS protein expression and NO levels in $\mathrm{H} 9 \mathrm{c} 2$ cells, and the NO blocker L-NAME significantly inhibited the cardioprotective effect of allicin against apoptosis. Therefore, we suggest that the antioxidative activity of allicin may be linked to activation of the eNOS/NO pathway.

\section{Conclusion}

Overall, our data indicate that allicin has powerful protective effects against $\mathrm{I} / \mathrm{H}$-induced cell apoptosis. The mechanism appears to involve an antioxidative effect that is mediated by the eNOS/NO pathway. Allicin treatment may be a promising clinical approach for IHD.

\section{Conflicts of Interest}

The authors declare no potential conflicts of interest with respect to the research, authorship, and/or publication of this article.

\section{Acknowledgments}

This study was supported by the Autonomous Region Major Science \& Technology Specific Projects: Innovation and Industrialization Demonstration of National Medicine (no. 2016A03005-1).

\section{References}

[1] X. Zhu and L. Zuo, "Characterization of oxygen radical formation mechanism at early cardiac ischemia," Cell Death \& Disease, vol. 4, no. 9, article e787, 2013.

[2] L. Ma, C.-C. Chuang, W. Weng et al., "Paeonol protects rat heart by improving regional blood perfusion during no-reflow," Frontiers in Physiology, vol. 7, article no. 298, 2016.

[3] V. Sivaraman and D. M. Yellon, "Pharmacologic therapy that simulates conditioning for cardiac ischemic/reperfusion injury," Journal of Cardiovascular Pharmacology and Therapeutics, vol. 19, no. 1, pp. 83-96, 2014.

[4] E. Teringova and P. Tousek, "Apoptosis in ischemic heart disease," Journal of Translational Medicine, vol. 15, no. 1, article no. 87, 2017.

[5] V. Boshra and A. Atwa, "Effect of cerebrolysin on oxidative stress-induced apoptosis in an experimental rat model of myocardial ischemia," Acta Physiologica Hungarica, vol. 103, no. 3, pp. 310-320, 2016.

[6] J. Narula, N. Haider, R. Virmani et al., "Apoptosis in myocytes in end-stage heart failure," The New England Journal of Medicine, vol. 335, no. 16, pp. 1182-1189, 1996.

[7] G. Olivetti, F. Quaini, R. Sala et al., "Acute myocardial infarction in humans is associated with activation of programmed myocyte cell death in the surviving portion of the heart," Journal of Molecular and Cellular Cardiology, vol. 28, no. 9, pp. 20052016, 1996.

[8] O. Dayoub, R. Andriantsitohaina, and N. Clere, "Pleiotropic beneficial effects of epigallocatechin gallate, quercetin and delphinidin on cardiovascular diseases associated with endothelial dysfunction," Cardiovascular \& Hematological Agents in Medicinal Chemistry, vol. 11, no. 4, pp. 249-264, 2013.

[9] X. U. Ying and Y. Zong-Ning, "Study on antioxidant activity of alliin, alliinase and their mixture in vitro," West China Journal of Pharmaceutical Sciences, vol. no. 04, pp. 328-330, 2011.

[10] S. J. Thomson, P. Rippon, C. Butts et al., "Inhibition of platelet activation by lachrymatory factor synthase (LFS)silenced (tearless) onion juice," Journal of Agricultural and Food Chemistry, vol. 61, no. 44, pp. 10574-10581, 2013.

[11] X. Zou, J. Liang, J. Sun et al., "Allicin sensitizes hepatocellular cancer cells to anti-tumor activity of 5-fluorouracil through ROS-mediated mitochondrial pathway," Journal of Pharmacological Sciences, vol. 131, no. 4, pp. 233-240, 2016.

[12] D. Wallock-Richards, C. J. Doherty, L. Doherty et al., "Garlic revisited: antimicrobial activity of allicin-containing garlic extracts against Burkholderia cepacia complex," PLoS ONE, vol. 9, no. 12, Article ID el12726, 2014. 
[13] L.-N. Ma, L.-D. Li, S.-C. Li et al., "Allicin improves cardiac function by protecting against apoptosis in rat model of myocardial infarction," Chinese Journal of Integrative Medicine, vol. 23, no. 8, pp. 589-597, 2017.

[14] Y. Liu, H. Qi, Y. Wang et al., "Allicin protects against myocardial apoptosis and fibrosis in streptozotocin-induced diabetic rats," Phytomedicine, vol. 19, no. 8-9, pp. 693-698, 2012.

[15] J. Y.-Y. Chan, A. C.-Y. Yuen, R. Y.-K. Chan, and S.-W. Chan, "A review of the cardiovascular benefits and antioxidant properties of allicin," Phytotherapy Research, vol. 27, no. 5, pp. 637-646, 2013.

[16] Y. J. Lee, D. Lee, S. M. Shin et al., "Potential protective effects of fermented garlic extract on myocardial ischemiareperfusion injury utilizing in vitro and ex vivo models," Journal of Functional Foods, vol. 33, pp. 278-285, 2017.

[17] D. Ilić, V. Nikolić, M. Stanković et al., “Transformation of synthetic allicin: the influence of ultrasound, microwaves, different solvents and temperatures, and the products isolation," The Scientific World Journal, vol. 2012, Article ID 561823, 7 pages, 2012.

[18] H. Wang, X. Li, X. Liu et al., "Influence of $\mathrm{pH}$, concentration and light on stability of allicin in garlic (Allium sativum L.) aqueous extract as measured by UPLC," Journal of the Science of Food and Agriculture, vol. 95, no. 9, pp. 1838-1844, 2015.

[19] M. S. Rahman, "Allicin and other functional active components in garlic: Health benefits and bioavailability," International Journal of Food Properties, vol. 10, no. 2, pp. 245-268, 2007.

[20] H. Fujisawa, K. Suma, K. Origuchi, H. Kumagai, T. Seki, and T. Ariga, "Biological and chemical stability of garlic-derived allicin," Journal of Agricultural and Food Chemistry, vol. 56, no. 11, pp. 4229-4235, 2008.

[21] G. Del Poeta, A. Venditti, M. I. Del Principe et al., "Amount of spontaneous apoptosis detected by $\mathrm{Bax} / \mathrm{Bcl}-2$ ratio predicts outcome in acute myeloid leukemia (AML)," Blood, vol. 101, no. 6, pp. 2125-2131, 2003.

[22] J. Martinou and R. J. Youle, "Mitochondria in apoptosis: Bcl-2 family members and mitochondrial dynamics," Developmental Cell, vol. 21, no. 1, pp. 92-101, 2011.

[23] S. M. Mosaad, S. A. Zaitone, A. Ibrahim, A. A. El-Baz, D. M. Abo-Elmatty, and Y. M. Moustafa, "Celecoxib aggravates cardiac apoptosis in L-NAME-induced pressure overload model in rats: Immunohistochemical determination of cardiac caspase-3, Mcl-1, Bax and Bcl-2," Chemico-Biological Interactions, vol. 272, pp. 92-106, 2017.

[24] O. Bar-Am, O. Weinreb, T. Amit, and M. B. H. Youdim, "Regulation of Bcl-2 family proteins, neutrophic factors, and APP processing in the neurorescue activity of propargylamine," The FASEB Journal, vol. 19, no. 13, pp. 1899-1901, 2005.

[25] Y. Wang, S. Wei, Y.-L. Wang et al., "Protective effects of circulating microvesicles derived from myocardial ischemic rats on apoptosis of cardiomyocytes in myocardial ischemia/ reperfusion injury," Oncotarget, vol. 8, no. 33, pp. 54572-54582, 2017.

[26] J. Lee, E. H. Bae, S. K. Ma, and S. W. Kim, "Altered Nitric Oxide System in Cardiovascular and Renal Diseases," Chonnam Medical Journal, vol. 52, no. 2, p. 81, 2016.

[27] M. C. De Waard, J. Van Der Velden, N. M. Boontje et al., "Detrimental effect of combined exercise training and eNOS overexpression on cardiac function after myocardial infarction," American Journal of Physiology-Heart and Circulatory Physiology, vol. 296, no. 5, pp. H1513-H1523, 2009.
[28] S. P. Jones, J. J. Greer, A. K. Kakkar et al., "Endothelial nitric oxide synthase overexpression attenuates myocardial reperfusion injury," American Journal of Physiology-Heart and Circulatory Physiology, vol. 286, no. 1, pp. H276-H282, 2004.

[29] X. L. Louis, R. Murphy, S. J. Thandapilly, L. Yu, and T. Netticadan, "Garlic extracts prevent oxidative stress, hypertrophy and apoptosis in cardiomyocytes: A role for nitric oxide and hydrogen sulfide," BMC Complementary and Alternative Medicine, vol. 12, article no. 140, 2012.

[30] N. A. Kelsey, H. M. Wilkins, and D. A. Linseman, "Nutraceutical antioxidants as novel neuroprotective agents," Molecules, vol.15, no. 11, pp. 7792-7814, 2010.

[31] X. Chen, S. Pang, J. Lin, J. Xia, and Y. Wang, "Allicin prevents oxidized low-density lipoprotein-induced endothelial cell injury by inhibiting apoptosis and oxidative stress pathway," BMC Complementary and Alternative Medicine, vol. 16, no. 1, article no. 133, 2016.

[32] M. Zhang, H. Pan, Y. Xu, X. Wang, Z. Qiu, and L. Jiang, "Allicin decreases lipopolysaccharide-induced oxidative stress and inflammation in human umbilical vein endothelial cells through suppression of mitochondrial dysfunction and activation of Nrf2," Cellular Physiology and Biochemistry, vol. 41, no. 6, pp. 2255-2267, 2017.

[33] L. Ma, X. Liu, Y. Zhao, B. Chen, X. Li, and R. Qi, "Ginkgolide $B$ reduces LOX-1 expression by inhibiting Akt phosphorylation and increasing Sirtl expression in oxidized LDL-stimulated human umbilical vein endothelial cells," PLoS ONE, vol. 8, no. 9, Article ID e74769, 2013.

[34] K. Itoh, N. Wakabayashi, Y. Katoh et al., "Keapl represses nuclear activation of antioxidant responsive elements by Nrf2 through binding to the amino-terminal Neh2 domain," Genes \& Development, vol. 13, no. 1, pp. 76-86, 1999.

[35] J. Y. Chan, H. Tsui, I. Y. Chung, R. Y. Chan, Y. Kwan, and S. Chan, "Allicin protects rat cardiomyoblasts ( $\mathrm{H} 9 \mathrm{c} 2$ cells) from hydrogen peroxide-induced oxidative injury through inhibiting the generation of intracellular reactive oxygen species," International Journal of Food Sciences and Nutrition, vol. 65, no. 7, pp. 868-873, 2014.

[36] J. Li, T. R. Billiar, R. V. Talanian, and Y. M. Kim, "Nitric oxide reversibly inhibits seven members of the caspase family via Snitrosylation," Biochemical and Biophysical Research Communications, vol. 240, no. 2, pp. 419-424, 1997.

[37] D. A. Wink, I. Hanbauer, M. C. Krishna, W. DeGraff, J. Gamson, and J. B. Mitchell, "Nitric oxide protects against cellular damage and cytotoxicity from reactive oxygen species," Proceedings of the National Acadamy of Sciences of the United States of America, vol. 90, no. 21, pp. 9813-9817, 1993. 


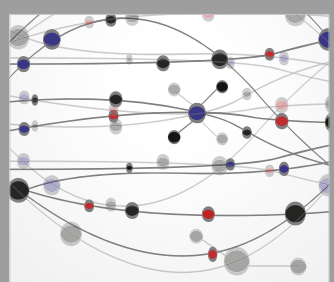

The Scientific World Journal
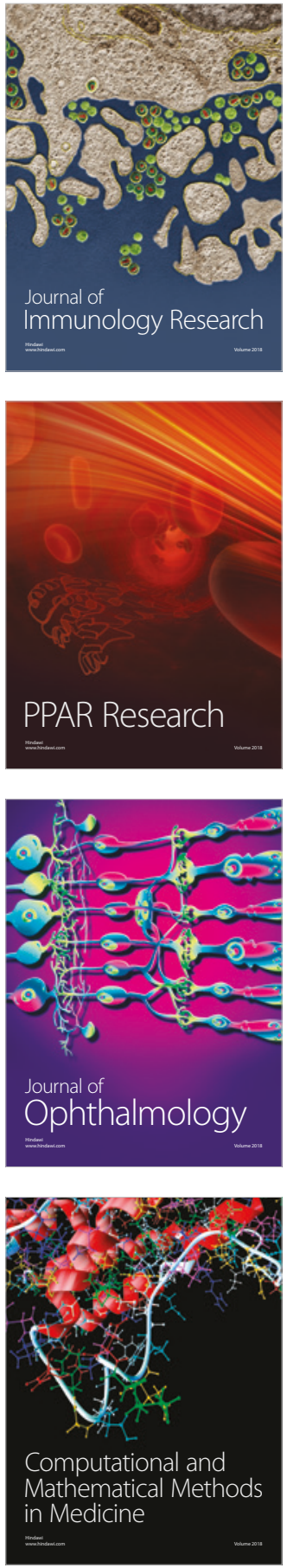

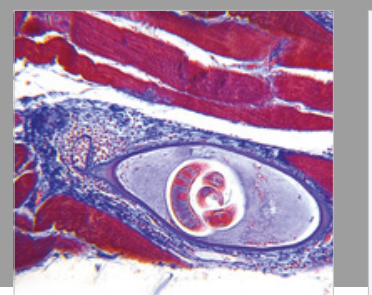

Gastroenterology Research and Practice

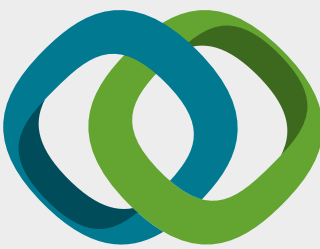

\section{Hindawi}

Submit your manuscripts at

www.hindawi.com
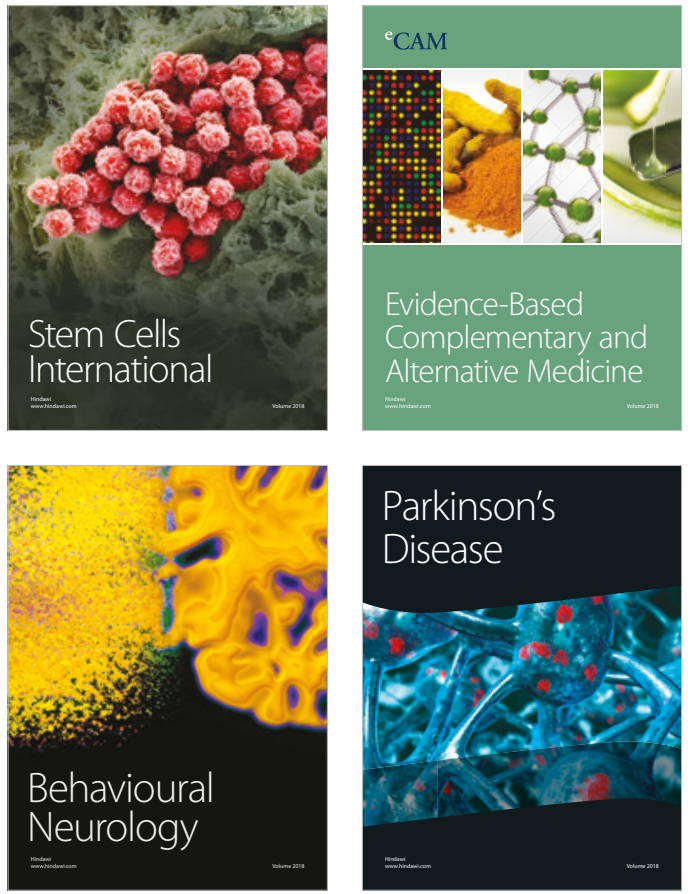

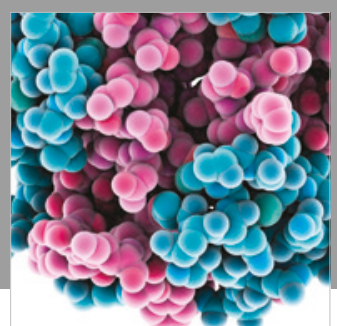

ournal of

Diabetes Research

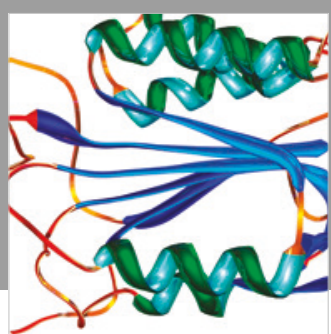

Disease Markers
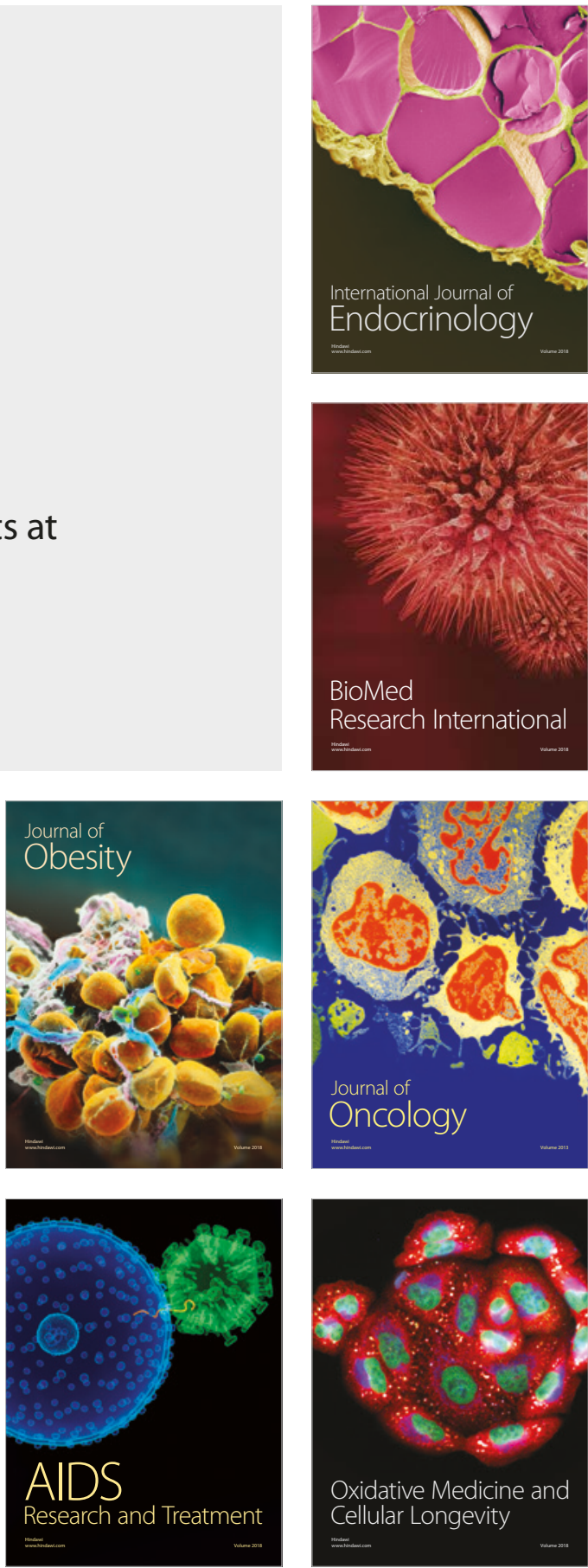